\title{
Informe de los Comités
}

\author{
AREA de MUJERES EN ÓPTICA Y FOTÓNICA \\ María Viñas, Verónica González-Fernández, Clara Benedí-García \\ Coordinadoras del área
}

DOI: dx.doi.org/10.7149/OPA.53.3.vi

\section{Documento de Recomendaciones a los Comités de SEDOPTICA para evitar el sesgo de género}

La investigación científica moderna depende de la colaboración diversa para el éxito. Este intercambio global e interdisciplinario de conocimiento debe ser ampliamente inclusivo, buscando contribuciones de todas las fuentes, basadas únicamente en la excelencia. La Sociedad Española de Óptica asume su propia diversidad y se compromete a ser también incluyente, esforzándose por brindar un ambiente en el que todas las personas se sientan valoradas y respetadas y tengan acceso a las mismas oportunidades. Somos una comunidad profesional al servicio de la comunidad humana en general.

Sin embargo, como individuos integrados en una sociedad, nuestras opiniones y criterios pueden terminar siendo sesgadas de forma inconsciente. Para evitar este sesgo inconsciente, en la última Junta de Gobierno de SEDOPTICA se aprobó un documento de recomendaciones generado por el Área de Mujeres de SEDOPTICA, en colaboración con su junta, y dirigido a los diferentes comités con el objetivo de eliminar los sesgos de género a la hora de organizar eventos/conferencias/webinars:

\section{Criterios en la organización de congresos y eventos científicos}

1. Ser conscientes de que, independientemente de nuestro género, tendremos una opinión sesgada. Por ello debemos entrenarnos y trabajar para minimizar los efectos negativos.

2. Intentar crear comités científicos los más paritarios posible.

3. Seleccionar ponentes invitados y plenarios cumpliendo criterios de equidad de género. Si no conocéis ponentes mujer cerca de vuestro círculo personal, preguntad a gente externa por sugerencias.

4. Cotejar que no se comete un sesgo de género en la selección de ponencias no invitadas.

5. Evaluar premios teniendo en cuenta criterios de inclusividad de género.

6. Informar a las personas encargadas de moderar las sesiones de que la solicitud de palabra por parte de asistentes femeninas pasa fácilmente desapercibida, para que sean conscientes y den voz a las mujeres en la sala durante el turno de preguntas.

7. El sesgo de género no sólo afecta a la composición del comité organizador o científico, los ponentes invitados o plenarios. El sesgo de género también afecta a las funciones y actividades asignadas a cada uno de los miembros de los comités. Desde, por ejemplo, asignar el trabajo más administrativo a mujeres mientras que las charlas de apertura o cierre, o las funciones de presidir o dirigir se asignan a hombres. Por ello, se recomienda, que se promueva la asignación de funciones de representación y liderazgo a investigadoras mujeres dentro de los comités.

8. Por otra parte, si la organización del evento requiere la contratación de personal de apoyo, se recomienda que la contratación de personal para funciones de servicio cómo, la suministración de micrófonos en la sala o el personal realizando el registro, sean de ambos géneros.

Desde la Sociedad Española de Óptica somos conscientes del esfuerzo a realizar por parte de los comités para llevar a cabo conferencias, seminarios, ciclos, etc., cumpliendo con la igualdad de género. Por ello agradecemos de antemano a los miembros su trabajo y su apoyo para conseguir una ciencia -en nuestro ámbito de la Óptica y Fotónica en España sin sesgo de género. 


\section{Recomendaciones}

Siendo los comités científicos de cada reunión científica los encargados de llevar a la práctica los criterios expuestos, el Área de Mujer en Óptica y Fotónica (SEDOPTICA-MOF) de la Sociedad Española de Óptica se encargará de analizar su aplicación y promover medidas de cara a que los diferentes eventos organizados en el entorno de SEDOPTICA puedan alcanzar los siguientes números:

- Comités científicos: al menos un 40\% de investigadoras, a no ser que la distribución de miembros de dicho comité sea muy inferior, de modo que ese número se vería corregido para ajustarse a la realidad del mismo.

- Comités de selección de premios: al menos un 40\% de investigadoras, a no ser que la distribución de miembros de dicho comité sea muy inferior, de modo que ese número se vería corregido para ajustarse a la realidad del mismo.

- Ponencias invitadas: al menos un 40\% de investigadoras.

- Contribuciones científicas: número de contribuciones de mujeres acorde al porcentaje de mujeres en el comité correspondiente.

Con objeto de alcanzar estos porcentajes se aportan las direcciones de las siguientes bases de datos para encontrar información acerca expertas en diferentes áreas de la óptica y la fotónica en España:

https://compromiso.atresmedia.com/constantes-vitales/mujerescientificas/buscador/

Aquí podéis descargar el documento, para tenerlo siempre a mano. Animamos a todos a seguir unas directrices como estas para conseguir una ciencia más igualitaria. Y recordad: \#SinCientíficAsNoHayFuturo

\section{"CientíficAs_Conectadas_2"}

El 23 de junio tuvimos el segundo webinar de nuestra serie "CientíficAs_Conectadas”, titulado "Manual de supervivencia para la carrera científica”. Este webinar estuvo protagonizado por la Dra. María Viñas, que expuso en primer lugar su charla "Cómo avanzar en tu carrera profesional: vivir, no sobrevivir" en la que expuso consejos prácticos para conseguir un buen currículum en las primeras fases de la carrera investigadora. La segunda charla, impartida por la Dra. Gloria González-Ramos, donde demostró con estudios sociales y de género ejemplos claros de discriminación que sufren las mujeres en el ámbito científico.

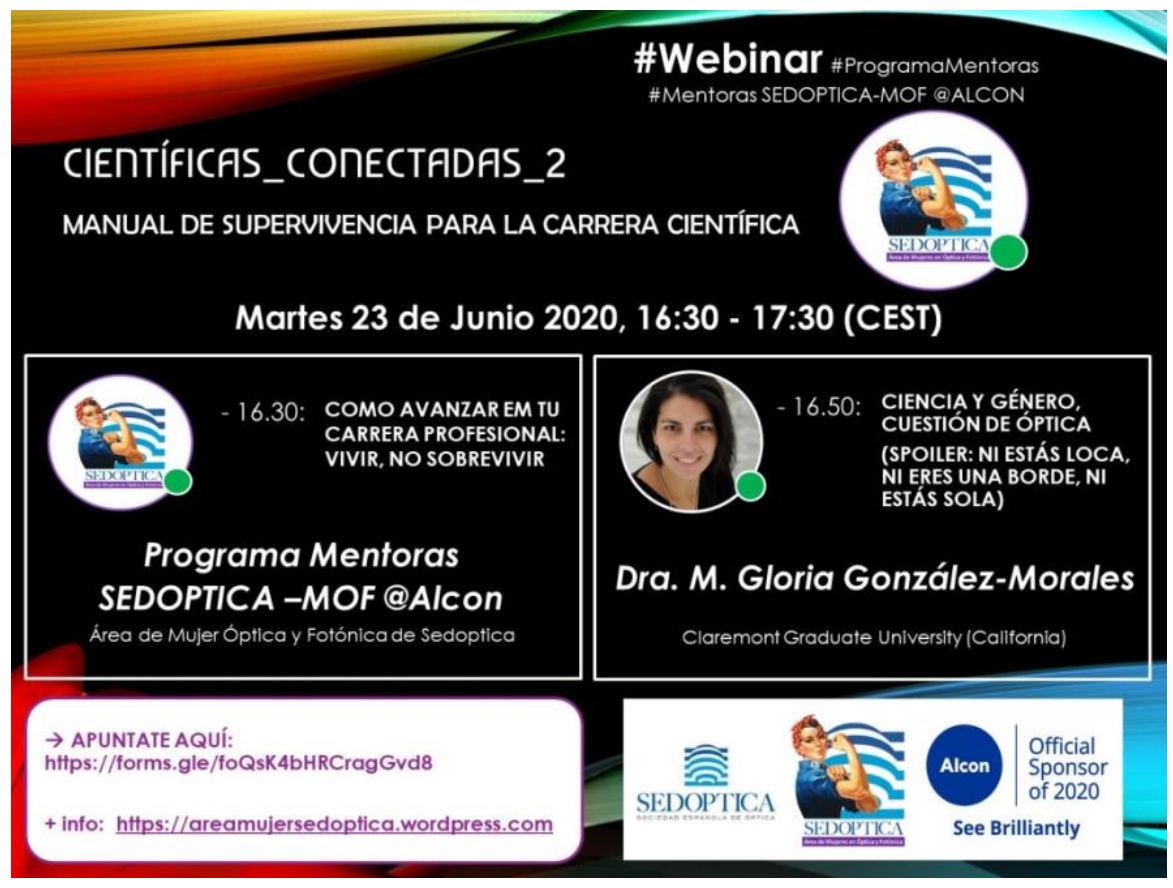


Este segundo webinar siguió la estela del primero, y contó con 60 asistentes que se conectaron estas charlas. Si no pudisteis asistir, el webinar completo está en el canal de Youtube de SEDOPTICA, donde ya cuenta con 52 visualizaciones.

\section{“Conoce a las Investigadoras"}

El programa Conoce a las Investigadoras sigue acumulando entrevistas. En estos meses estivales hemos entrevistado a las siguientes investigadoras:

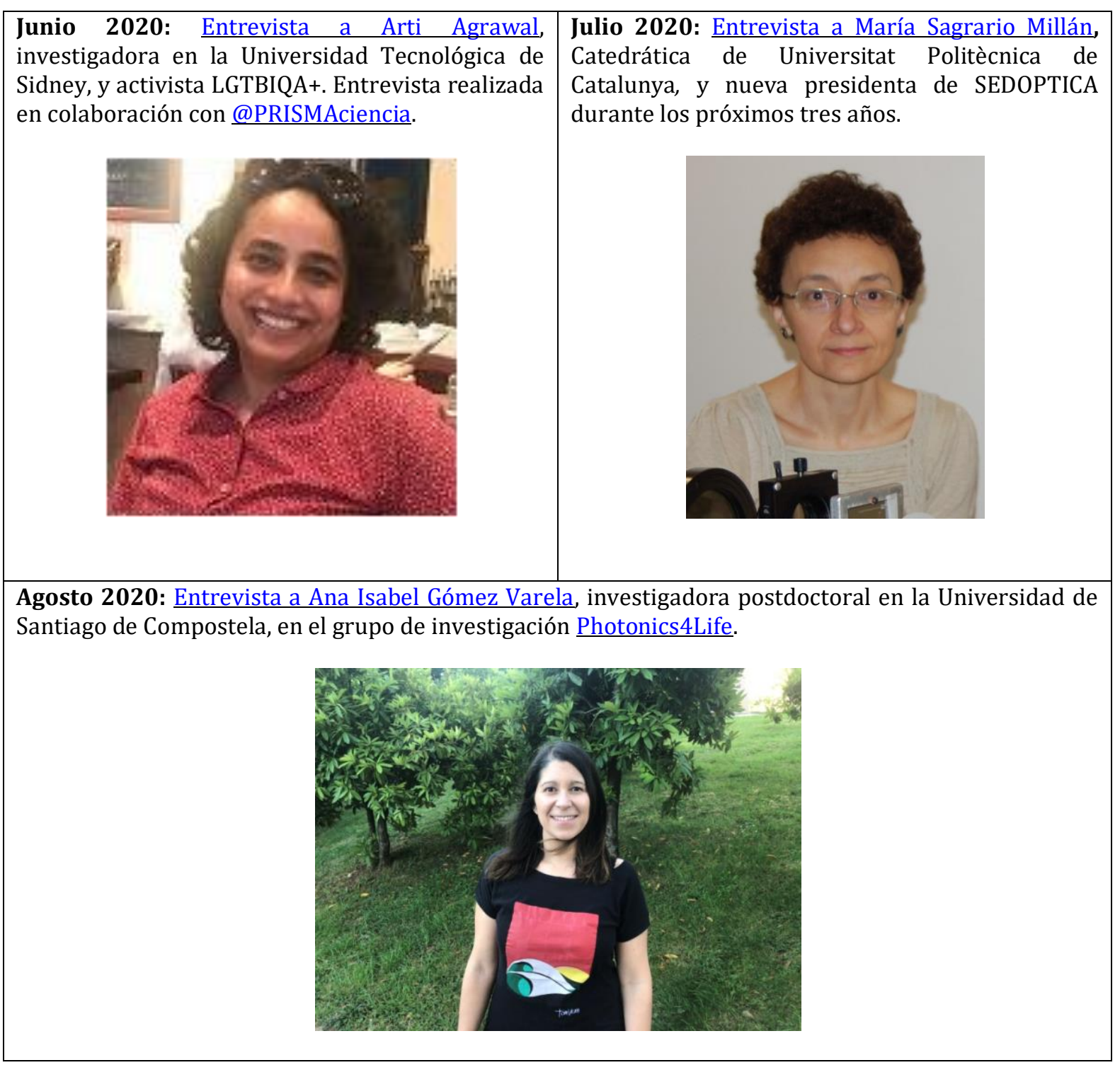

¡No os las perdáis! ¡Y compartidlas! 


\title{
Los Comités Informan
}

\section{ACTO CENTRAL EN ESPAÑA DEL DÍA INTERNACIONAL DE LA LUZ EN LA FACULTAD DE ÓPTICA Y OPTOMETRÍA DE TERRASSA}

\author{
Elisabet Pérez Cabré
}

\author{
Presidenta del Comité Organizador del DIL 2020-2021 en Terrassa
}

La Facultad de Óptica y Optometría de Terrassa (FOOT) fue designada por el Comité español del Día Internacional de la Luz (DIL) como la sede de la 3a edición del Acto Central en España en el año 2020, después de las exitosas celebraciones de Madrid y Santiago de Compostela en los años precedentes. Sin embargo, como muchos otros acontecimientos, nos vimos obligados a adaptar esta celebración a la situación de emergencia sanitaria debida a la pandemia del COVID-19. El Comité organizador local, trabajando estrechamente con el Comité español del DIL, y siguiendo la convocatoria internacional del International Day of Light de compartir imágenes relacionadas con la luz en las redes sociales, organizó un concurso fotográfico entre los días 10 y 20 de mayo a través de Instagram.

La respuesta fue muy positiva, recibiendo casi 300 fotografías etiquetadas con \#dil2020terrassa durante los días de participación al concurso y reuniendo casi 200 nuevos seguidores en la cuenta de Instagram (@DIL20_21Terrassa). Fotografías muy diversas con la luz como motivo común en todas ellas. Fue difícil para el jurado, a quién agradecemos su tarea, elegir las fotografías finalistas, y entre ellas, la ganadora del concurso, Ginger Candelario (@gingercabu), a quién felicitamos nuevamente por su original composición de fenómenos ópticos y visuales.

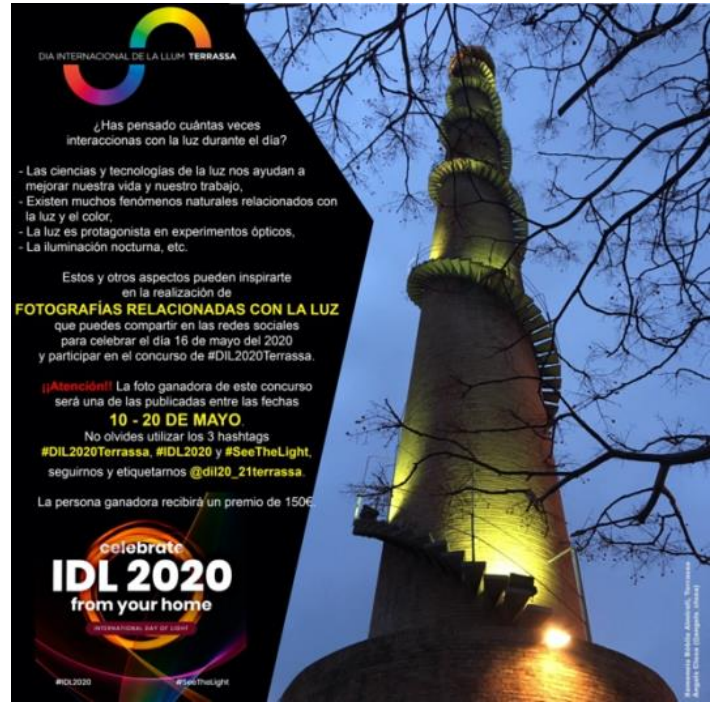

(a)

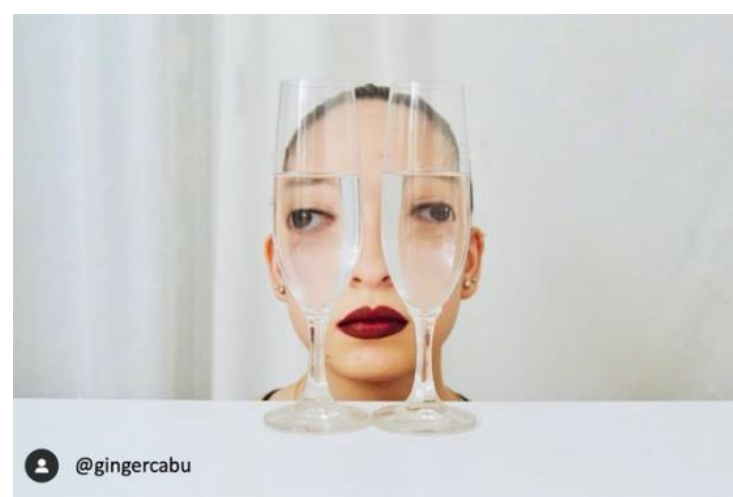

(b)

Fig. 1 (a) Cartel anunciador del concurso fotográfico. (b) Fotografía ganadora de Ginger Candelario (@gingercabu).

Sin duda, el éxito de participación no se hubiera conseguido sin la promoción del concurso desde numerosos ámbitos. Desde la misma web del Comité Español del DIL (diadelaluz.es), hasta las redes sociales de diversas entidades, empresas e investigadores (SEDOPTICA y su área joven, COOOC, IOT, FOOT, Secpho, Ajuntament de Terrassa, Fotónica 21 y demás colaboradores del DIL), a los que agradecemos enormemente su ayuda en difundir el evento. Cabe destacar de manera especial, las iniciativas, por un lado, del Sincrotrón ALBA publicando imágenes relacionadas con "las luces del Sincrotón" (@alba_synchrotron) durante los días del concurso y también del OSA chapter del Instituto de Óptica de Madrid (@iosa_chapter) que compartieron imágenes relacionadas con la luz durante todo el día 16 de mayo. 


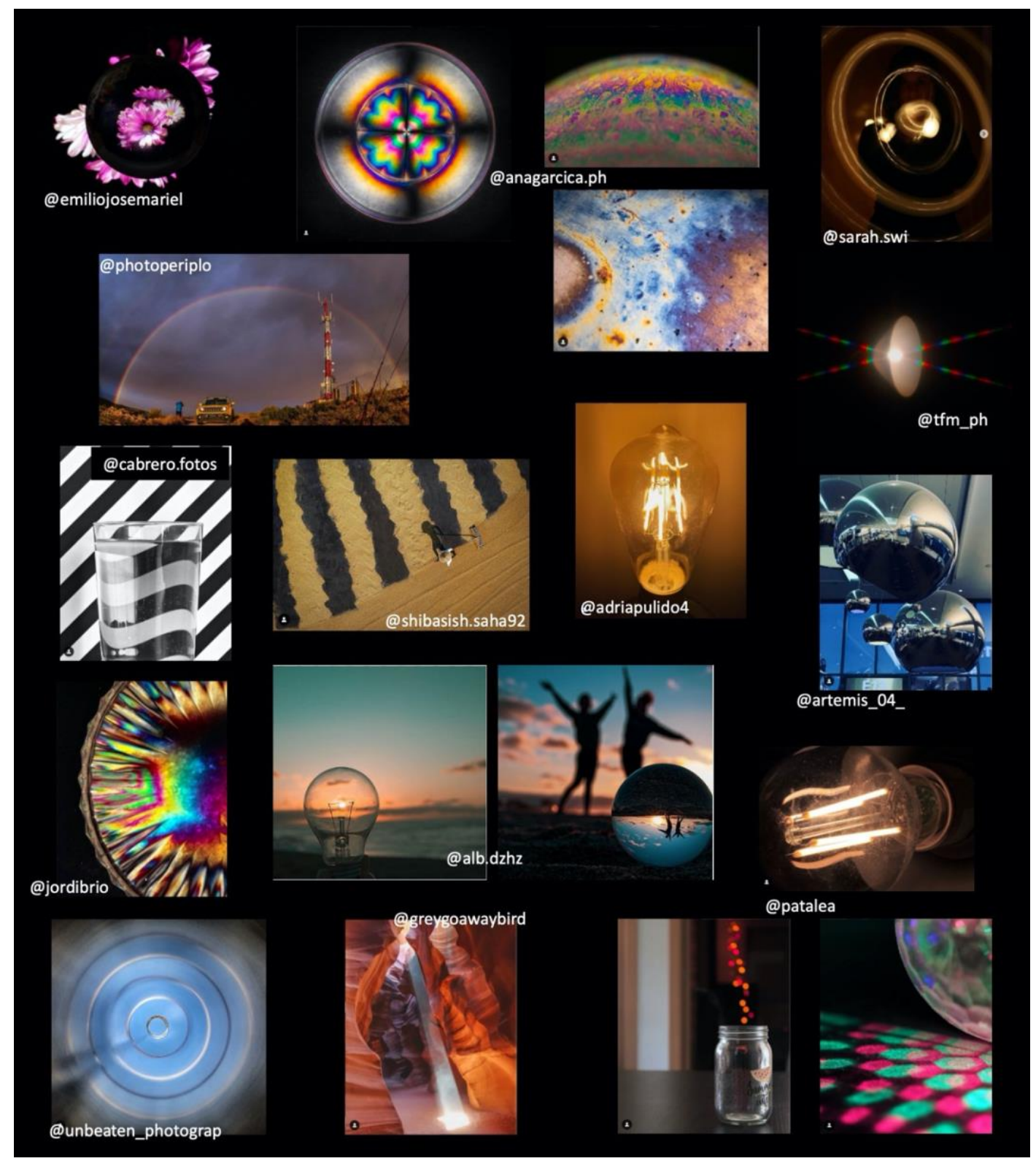

Fig. 2 Fotografías finalistas del concurso.

Una vez pasado este singular Día Internacional de la Luz, el Comité organizador local sigue trabajando en la preparación del Acto Central en España que se celebrará como edición conjunta 2020-2021 en mayo del año próximo en la ciudad de Terrassa. Mantenemos el énfasis en la Luz como estímulo de la Visión y la necesidad de mantener una buena Salud Visual. Las actividades serán muy diversas desde conferencias divulgativas, debates y mesas redondas sobre temas de actualidad, talleres experimentales lúdicos, espectáculos históricos y culturales. ¡Os esperamos a todos! 


\title{
Los Comités Informan
}

\section{COMITÉ DE OPTICA CUÁNTICA Y OPTICA NO LINEAL (QUONLOP)}

\author{
Ramon Vilaseca Alavedra, Roberta Zambrini y Ángel Paredes Galán \\ Coordinadores del Comité de Óptica Cuántica y Óptica No Lineal
}

Desde las juntas directivas de QUONLOP (el comité de óptica cuántica y óptica no lineal de SEDOPTICA) y GEOCONOL (el grupo especializado de igual nombre en la RSEF), que vienen funcionando conjuntamente desde el año 2014, queremos informar de dos novedades.

La primera es la puesta en marcha de la página web de QUONLOP/GEOCONOL que podéis visitar aquí https://quonlop-geoconl.icfo.eu/. Esta página, albergada por el Institut de Ciències Fotòniques (ICFO), ha sido creada con la vocación de servir de herramienta útil a nuestra comunidad y os animamos a participar en su mejora enviando noticias, ofertas y sugerencias a quonlop@sedoptica.es.

La segunda novedad es la creación de los Premios Ramón Corbalán: con el fin de recordar la figura del Prof. Ramón Corbalán Yuste, en particular su apreciada tarea como docente, investigador y gestor científico, se establecen los Premios Ramón Corbalán de Divulgación y Enseñanza de la Óptica Cuántica y la Óptica No Lineal, destinados a fomentar la actividad de divulgación de la ciencia en dichos campos u o campos afines en nuestro país, en especial por parte de jóvenes investigadores.

Los premios se presentan en tres modalidades:

a) Premio Ramón Corbalán a la divulgación y la enseñanza, que premia artículos de divulgación.

b) Premio Ramón Corbalán a la divulgación de tesis doctorales, que premia artículos de divulgación de tesis doctorales.

c) Premio Ramón Corbalán a la divulgación joven, que premia trabajos divulgativos realizados por estudiantes de grado, posgrado o doctorado.

Más específicamente, la modalidad a) premiará artículos aparecidos en las revistas de nuestras Sociedades, Óptica Pura y Aplicada y Revista Española de Física, así como en otras revistas científicas publicadas en España o en medios periodísticos españoles de calidad (1). Los artículos podrán ser de divulgación científica o de enseñanza (e.g. tutoriales sobre un tema o artículos docentes). Se admiten artículos escritos en castellano, inglés o cualquier lengua cooficial de las comunidades autónomas, pudiendo los jurados solicitar a las candidatas o candidatos traducción del texto original. Se premiará un artículo por edición.

(1) Por defecto se considerarán los trabajos aparecidos en Revista Española de Física y en Óptica Pura y Aplicada en los tres años anteriores al de la convocatoria. Artículos aparecidos en otras revistas habrán de ser sometidos al premio.

La modalidad b) premiará los trabajos de tesis doctorales a través de su divulgación. Se considerarán artículos de autoría única en los que la doctoranda o doctorando haga una presentación divulgativa de su tesis doctoral. Se premiará un artículo por edición.

La modalidad c) premiará trabajos breves dirigidos a divulgar conceptos de Óptica Cuántica y Óptica No Lineal, habiendo de ser estudiantes sus autores (de grado, máster o doctorado). Todos los conceptos (2) se publicarán en la página web de los Comités, y los que sean premiados se publicarán, además, en Revista Española de Física y en Óptica Pura y Aplicada. Se premiarán dos conceptos por edición.

(2) Concepto: breve descripción divulgativa de un concepto de Óptica Cuántica o de Óptica No Lineal, con un texto de un máximo de 500 palabras con la opción de adjuntar una figura.

La de 2020 es la primera edición de los Premios Ramón Corbalán que se entregarán en la Reunión Nacional de Óptica de 2021 en Valencia y que en esta primera edición cuentan con el patrocinio de The Optical Society OSA y del Centro de Láseres Pulsados (CLPU) de Salamanca. En nuestra página web se encuentra toda la información. ¡Os animamos a participar enviando vuestros trabajos! 


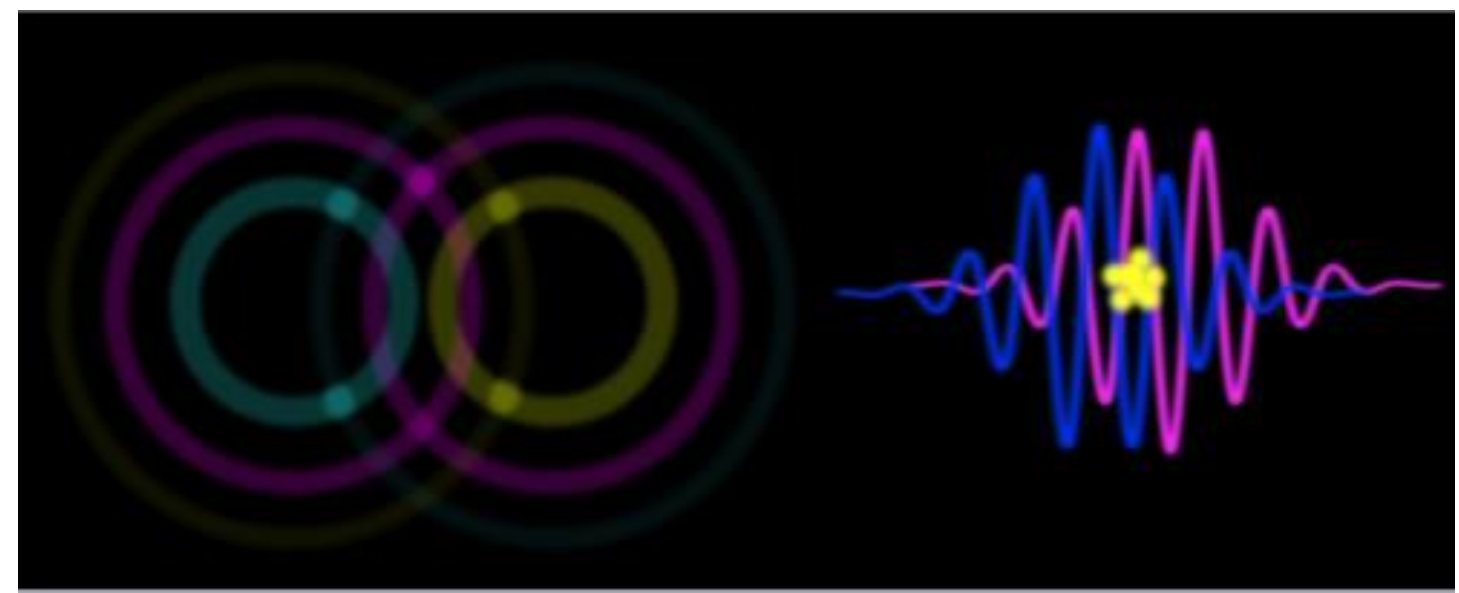

\section{PrEmIOS RAMÓN GORBaLán DE DIVULGACIÓN Y ENSEÑANZA}

\section{DE LA ÓPTICA GUÁNTIIGA Y LA ÓPTIGA NO LINEAL}

a) Divulgación y enseñanza.

3 modalidades: (1 premio de 3006)

b) Divulgación de fesis doctorales. (1 premio de 300e)

c) Divulgación joven.

(2 premios de 1006)

Fecha limite de presentación de solicitudes:

28 de Febrero de 2021.

\section{Organizan:}

QUONLOP

Comité de Óptica Cuántica y

Óptica no Lineal

\section{GEOCONL}

Grupo Especializado en Óptica

Cuántica y Óptica no Lineal

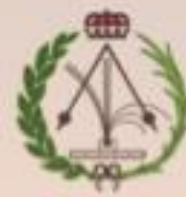

Real

Sociedad

Española de

Fisica

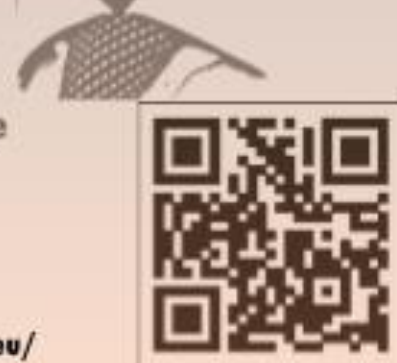

*Consultar las bases completas de los premios en: https://rsef-geoconl.icfo.ev/ 